\title{
Downregulation of the NbNACa1 Gene Encoding a Movement-Protein-Interacting Protein Reduces Cell-to-Cell Movement of Brome mosaic virus in Nicotiana benthamiana
}

\author{
Masanori Kaido, ${ }^{1}$ Yosuke Inoue, ${ }^{1}$ Yoshika Takeda, ${ }^{1}$ Kazuhiko Sugiyama, ${ }^{1}$ Atsushi Takeda, ${ }^{1}$ \\ Masashi Mori, ${ }^{2}$ Atsushi Tamai, ${ }^{3}$ Tetsuo Meshi, ${ }^{3}$ Tetsuro Okuno, ${ }^{1}$ and Kazuyuki Mise ${ }^{1}$ \\ ${ }^{1}$ Laboratory of Plant Pathology, Graduate School of Agriculture, Kyoto University, Kyoto 606-8502, Japan; ${ }^{2}$ Laboratory \\ of Plant Molecular Genetics, Research Institute of Agricultural Resources, Ishikawa Agricultural College, 1-308, Suematsu, \\ Nonoichi-machi, Ishikawa 951-8836, Japan; ${ }^{3}$ National Institute of Agrobiological Sciences, Tsukuba, Ibaraki 305-8602, Japan
}

Submitted 20 November 2006. Accepted 3 January 2007.

The 3a movement protein (MP) plays a central role in the movement of the RNA plant virus, Brome mosaic virus (BMV). To identify host factor genes involved in viral movement, a cDNA library of Nicotiana benthamiana, a systemic host for BMV, was screened with far-Western blotting using a recombinant BMV MP as probe. One positive clone encoded a protein with sequence similarity to the $\alpha$ chain of nascent-polypeptide-associated complex from various organisms, which is proposed to contribute to the fidelity of translocation of newly synthesized proteins. The orthologous gene from $N$. benthamiana was designated NbNACa1. The binding of NbNACa1 to BMV MP was confirmed in vivo with an agroinfiltration-immunoprecipitation assay. To investigate the involvement of NbNACa1 in BMV multiplication, NbNACa1-silenced (GSNAC) transgenic $N$. benthamiana plants were produced. Downregulation of $\mathrm{NbNACa1}$ expression reduced virus accumulation in inoculated leaves but not in protoplasts. A microprojectile bombardment assay to monitor BMV-MP-assisted viral movement demonstrated reduced virus spread in GSNAC plants. The localization to the cell wall of BMV MP fused to green fluorescent protein was delayed in GSNAC plants. From these results, we propose that NbNACa1 is involved in $\mathrm{BMV}$ cell-to-cell movement through the regulation of BMV MP localization to the plasmodesmata.

Additional keywords: $\alpha-\mathrm{NAC}$.

Plant cells are interconnected via intercellular cytoplasmic channels called plasmodesmata (PD), and exchange various low molecular weight materials such as ions and phytohormones. High molecular weight materials, such as the plant proteins of the non-cell-autonomous pathway, also are trafficked through the PD, and this trafficking is important for the developmental regulation of plants (Kim et al. 2003; Lucas et al. 1995;

Corresponding author: Kazuyuki Mise; Telephone +81.75 .753 .6132 ; Fax +81.75.753.6131; E-mail: kmise@kais.kyoto-u.ac.jp

Current address of A. Takeda: Department of Life Sciences, University of Tokyo, Komaba 3-8-1, Meguro, Tokyo 153-8902, Japan.

Nucleotide sequence data is available in the DDBJ/EMBL/GenBank databases under accession number AB201544.
Nakajima et al. 2001; Sessions et al. 2000; Zambryski 2004). Plant viruses exploit PD and spread from the initially infected cell to neighboring cells (cell-to-cell movement), which is an essential step in the early stage of viral systemic infection of their host plants. Virus-encoded movement proteins (MPs) play central roles in cell-to-cell movement. Although there is great diversity in the amino acid sequences of MPs (Melcher 2000) and in the modes of viral cell-to-cell movement (Scholthof 2005), MPs have in common the functions that they bind to nucleic acids, target the PD, and enlarge the size exclusion limit of the PD (Lucas 2006; Waigmann et al. 2004). To achieve these functions, MPs are thought to require compatible interactions with host plant components (Lazarowitz and Beachy 1999; Lucas 2006; McLean et al. 1997; Waigmann et al. 2004). To date, many host plant proteins that bind to MPs have been identified (Waigmann et al. 2004) and several of them have been shown to influence viral movement. In the case of Tobacco mosaic virus (TMV), a tobacco cell wall enzyme, pectin methyl esterase, is involved in its systemic movement via its regulation of viral unloading from the phloem tissue (Chen and Citovsky 2003; Chen et al. 2000; Dorokhov et al. 1999). Another tobacco cell wall protein, calreticulin, promotes microtubule association with the MP and negatively regulates the targeting of TMV MP to the PD and viral cell-to-cell movement (Chen et al. 2005). Another example is the microtubule-associated MPB2C protein, which negatively regulates TMV cell-tocell movement through the association of MP along the microtubule (Kragler et al. 2003). The microtubule itself also interacts directly with TMV MP and is thought to play a role in the intercellular spread of TMV infection (Ashby et al. 2006). Identification of the host factor proteins involved in viral cellto-cell movement and the elucidation of their functions in the movement process should contribute to our understanding of the viral movement mechanism and of the plant endogenous protein trafficking mechanism.

Brome mosaic virus (BMV), the type species of the genus Bromovirus in the family Bromoviridae, is one of the most thoroughly investigated positive-strand plant RNA viruses. The cell-to-cell movement of BMV is mediated by the nonstructural $3 \mathrm{a} \mathrm{MP}$, and the coat protein (CP) also is required as an auxiliary protein by the M1 strain (Okinaka et al. 2001; Schmitz and Rao 1996; Takeda et al. 2004). BMV MP has been characterized to clarify the BMV movement mechanism. BMV MP binds to single-stranded RNA in vitro, and localizes 
to the PD (Fujita et al. 1998) and cytoplasmic inclusions, together with BMV replication component proteins $1 \mathrm{a}$ and $2 \mathrm{a}$ (Dohi et al. 2001) in BMV-infected barley plants. Alaninescanning mutagenesis of the BMV MP gene clarified the func- tional domains important for the movement of BMV (Takeda et al. 2004). Yeast two-hybrid screening using BMV CP as bait identified a barley protein, $\mathrm{HCP} 1$, that is involved in viral movement (Okinaka et al. 2003).

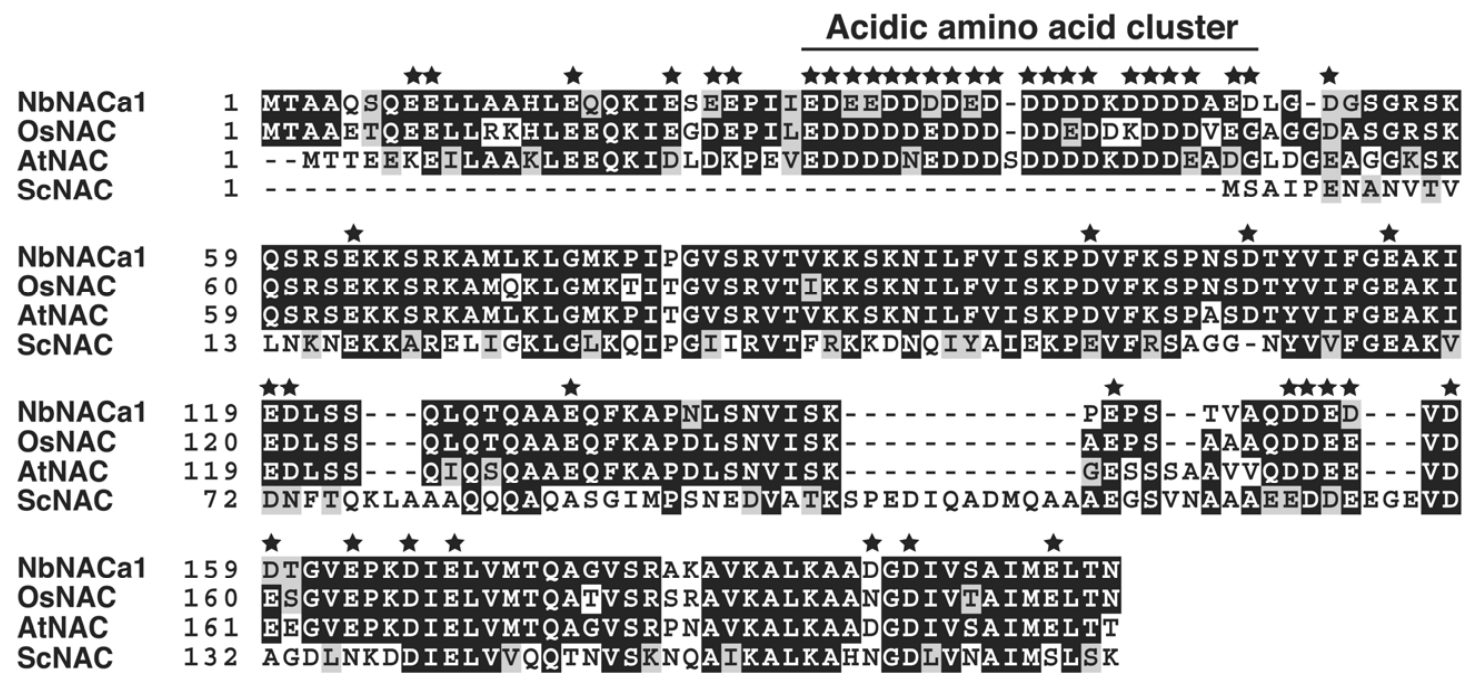

Fig. 1. Comparison of the amino acid sequences of the $\alpha$ chains of the nascent-polypeptide-associated complex ( $\alpha$-NAC) of various organisms. NbNACa1, $\alpha$-NAC ortholog of Nicotiana benthamiana; OsNAC, $\alpha$-NAC of Oryza sativa (P0504E02.25); AtNAC, $\alpha-\mathrm{NAC}$ of Arabidopsis thaliana (At3g12390); and ScNAC, $\alpha$-NAC of Saccharomyces cerevisiae. Asterisks represent acidic amino acids in NbNACa1 (aspartic acid and glutamic acid). Identical amino acid residues are shaded in black and similar residues in gray.

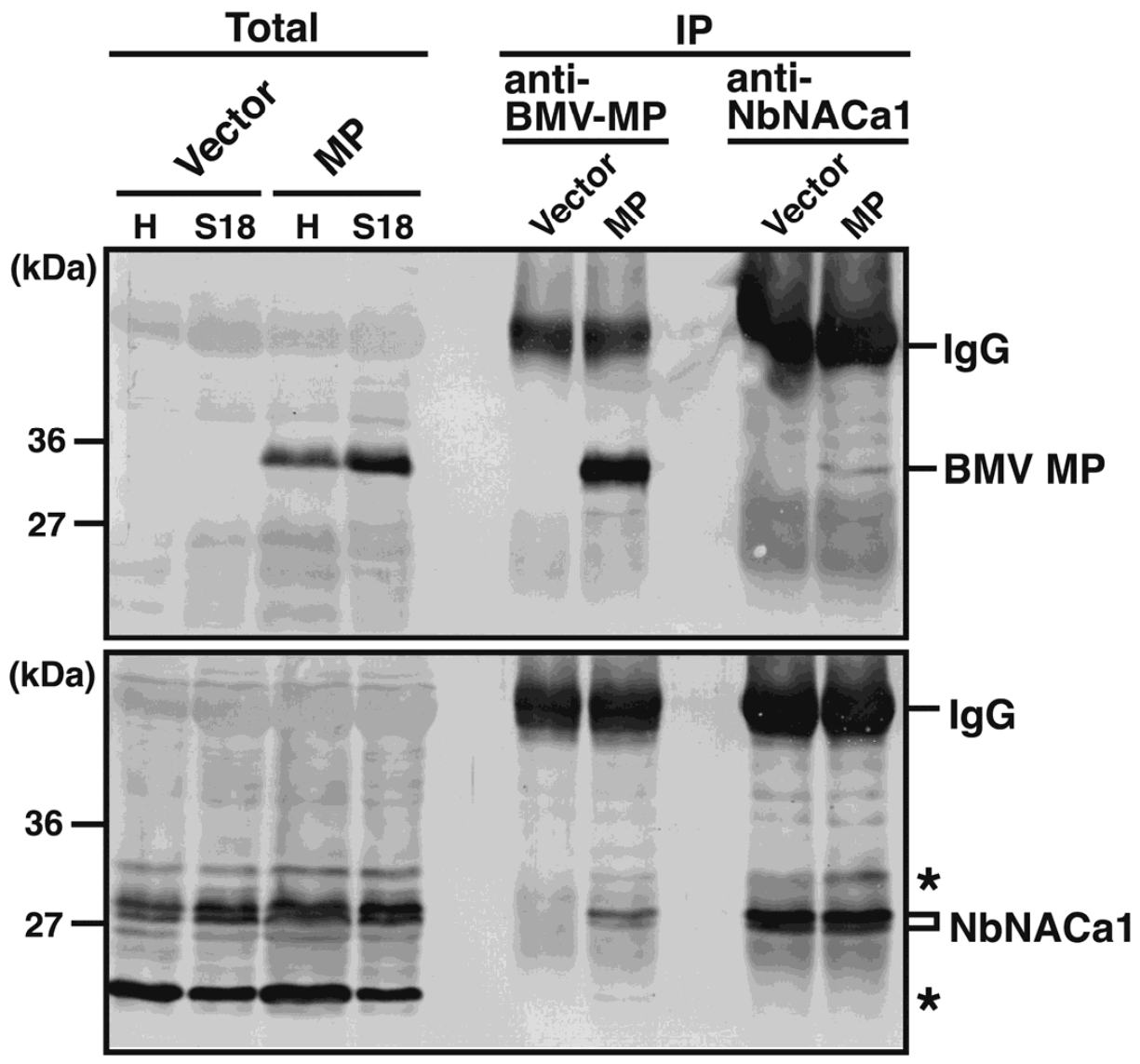

Fig. 2. NbNACa1 interacts with Brome mosaic virus (BMV) movement protein (MP) in vivo. GS1 plant leaves infiltrated with Agrobacterium cultures containing plasmid expressing BMV MP (MP) or negative control vector (vector) were subjected to immunoprecipitation with antiserum directed against BMV MP (anti-BMV-MP) or NbNACa1 (anti-NbNACa1). Protein samples before (Total) and after (IP) immunoprecipitation were subjected to sodium dodecyl sulfate polyacrylamide gel electrophoresis and Western blot analysis using antiserum directed against BMV MP (upper panel) or NbNACa1 (lower panel). Lanes containing protein samples before immunoprecipitation were loaded with total hommogenate protein samples $(\mathrm{H})$ and the $18,000 \times g$ supernatant fraction (S18) from $5 \mathrm{mg}$ fresh weight of leaves. Lanes containing immunoprecipitated proteins were loaded with fraction from $200 \mathrm{mg}$ fresh weight of leaves. IgG represents rabbit immunoglobulin G. Asterisks represent nonspecifically detected proteins. Molecular weight marker sizes are indicated to the left. 
To further investigate the host factors involved in BMV cellto-cell movement, we screened a cDNA library of Nicotiana benthamiana, a systemic host of BMV (Mise et al. 1993), with far-Western blotting using ${ }^{32} \mathrm{P}$-labeled BMV MP as the probe. One isolated candidate gene encodes a protein sharing similarity with the $\alpha$ chain of the nascent-polypeptide-associated complex ( $\alpha-\mathrm{NAC})$. We designated this gene $\mathrm{NbNACal}$ and further investigated its involvement in BMV multiplication using transgenic $N$. benthamiana plants in which the expression of the gene was silenced. A set of data suggests that NbNACa1 is involved in the cell-to-cell movement of BMV through the regulation of MP localization to the PD.

\section{RESULTS}

Identification of $\alpha$-NAC protein as the BMV MP interactor by far-Western screening of an $N$. benthamiana cDNA library.

To identify $N$. benthamiana proteins that interact with BMV $\mathrm{MP}$, we screened an $N$. benthamiana cDNA library by far-
Western blotting using a ${ }^{32} \mathrm{P}$-labeled glutathione-S transferase (GST)-BMV MP fusion protein as the probe. cDNAs were synthesized from mRNA extracted from the expanded leaves of healthy $N$. benthamiana plants and integrated into the $\lambda$ GEX5 phage genome (Fukunaga and Hunter 1997). The resulting cDNA library expressed $N$. benthamiana proteins as GST-fusion proteins. Out of $6 \times 10^{5}$ plaques, 75 plaques finally were selected as positive clones. The plasmids were excised from the $\lambda$ DNA prepared from these plaques and were introduced into Escherichia coli XL1-Blue. The expression of the GST-fusion proteins was confirmed by Western blotting using anti-GST antibody (data not shown). Clones expressing GSTfusion proteins with similar electrophoretic mobility to that of nonfused GST were eliminated. Thus, 17 positive clones finally were selected (data not shown).

One positive clone encoded a polypeptide of 151 amino acids with sequence similarity to that of $\alpha$-NAC of various organisms. The gene was designated $\mathrm{NbNACal}$ and further characterized. The $5^{\prime}$ region of the $N b N A C a l$ gene was determined by $5^{\prime}$ RACE and the deduced amino acid sequence had high similar-

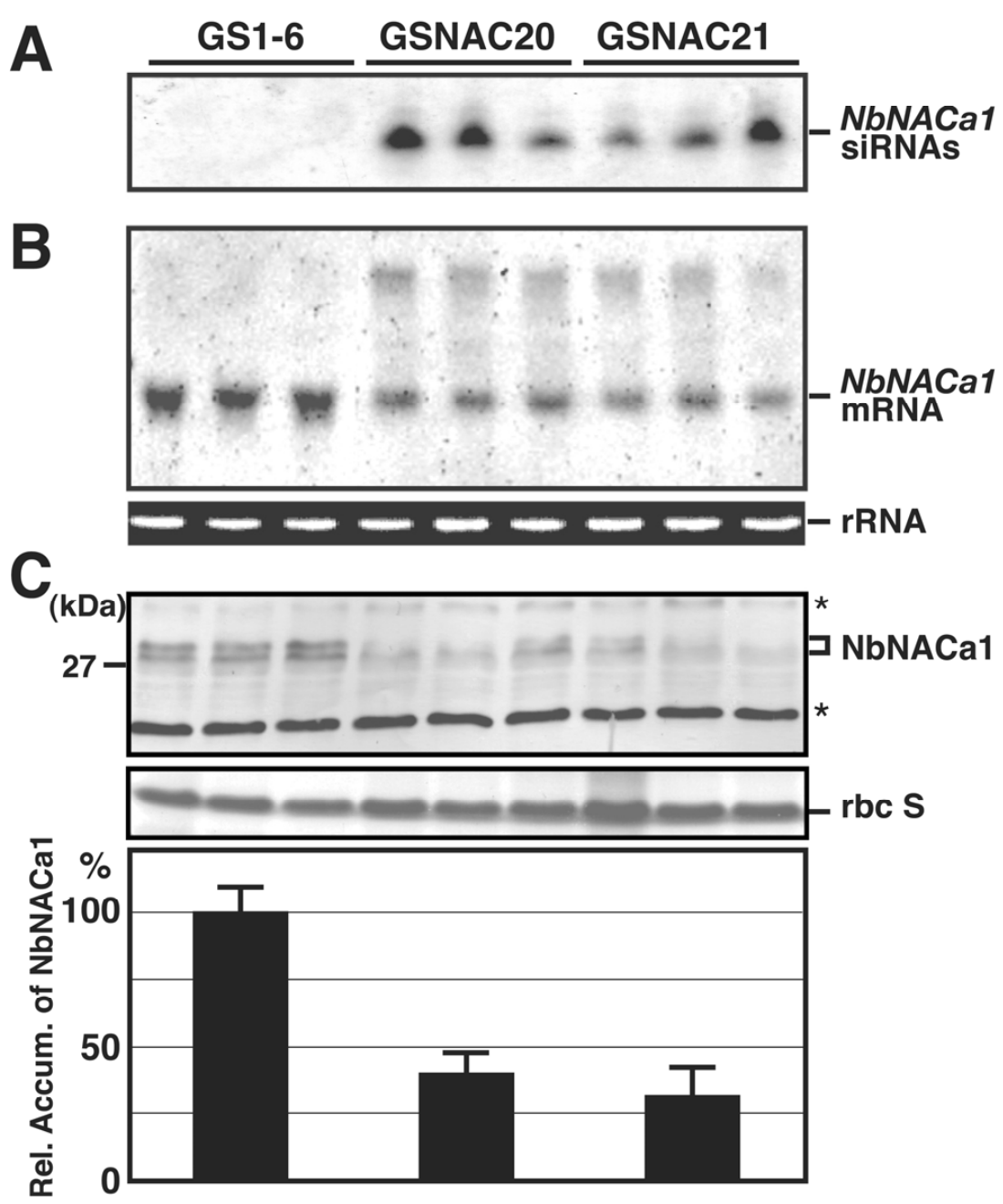

Fig. 3. Characterization of transgenic Nicotiana benthamiana plants. Three independent plants of GS1 plant line 6 and GSNAC plant lines 20 and 21 were used. A, Detection of small interfering (si)RNAs for $N b N A C a l$. Total RNA $(20 \mu \mathrm{g})$ was loaded in each lane and probed with ${ }^{32} \mathrm{P}-l$ labeled RNA probe complementary to the $3^{\prime} 634$ nucleotides (nt) of the $N b N A C a l$ gene. B, Detection of NbNACal mRNA by Northern blotting. Total RNA (5 $\left.\mu \mathrm{g}\right)$ was loaded in each lane and probed with a digoxigenin-labeled RNA probe complementary to the $3^{\prime} 634 \mathrm{nt}$ of the NbNACa1 gene. The intensity of the ethidium-bromide-stained band of rRNA indicates the relative amounts of samples loaded. C, Upper panel: detection of NbNACa1 by Western blotting. Leaf proteins (1 mg fresh weight of leaves) were loaded into each lane. Two NbNACa1-related bands and two nonspecific bands (asterisks) were detected. The intensity of the Coomassie Brilliant Blue-stained band of the small subunit of Rubisco ( $r b c \mathrm{~S}$ ) indicates the relative amounts of sample loaded. Molecular weight marker size is indicated to the left. Lower panel: summarized data from repeated Western blotting experiments. Membranes were scanned with a scanner (GT-8700F, Epson) and the protein signals were measured using NIH Image (version 1.61; National Institutes of Health, Bethesda, MD, U.S.A.). Data are the averages \pm standard error of three replicates, each containing three leaves from independent plants. 
ity to plant $\alpha$-NAC orthologs (Fig. 1). NbNACa1 (201 amino acids) is up to $92.5 \%$ similar to Oryza sativa $\alpha$-NAC (accession number NP_914976) and $88.6 \%$ similar to Arabidopsis thaliana $\alpha$-NAC (accession number NP_187845). These $\alpha$ NAC proteins contain characteristic clusters of acidic amino
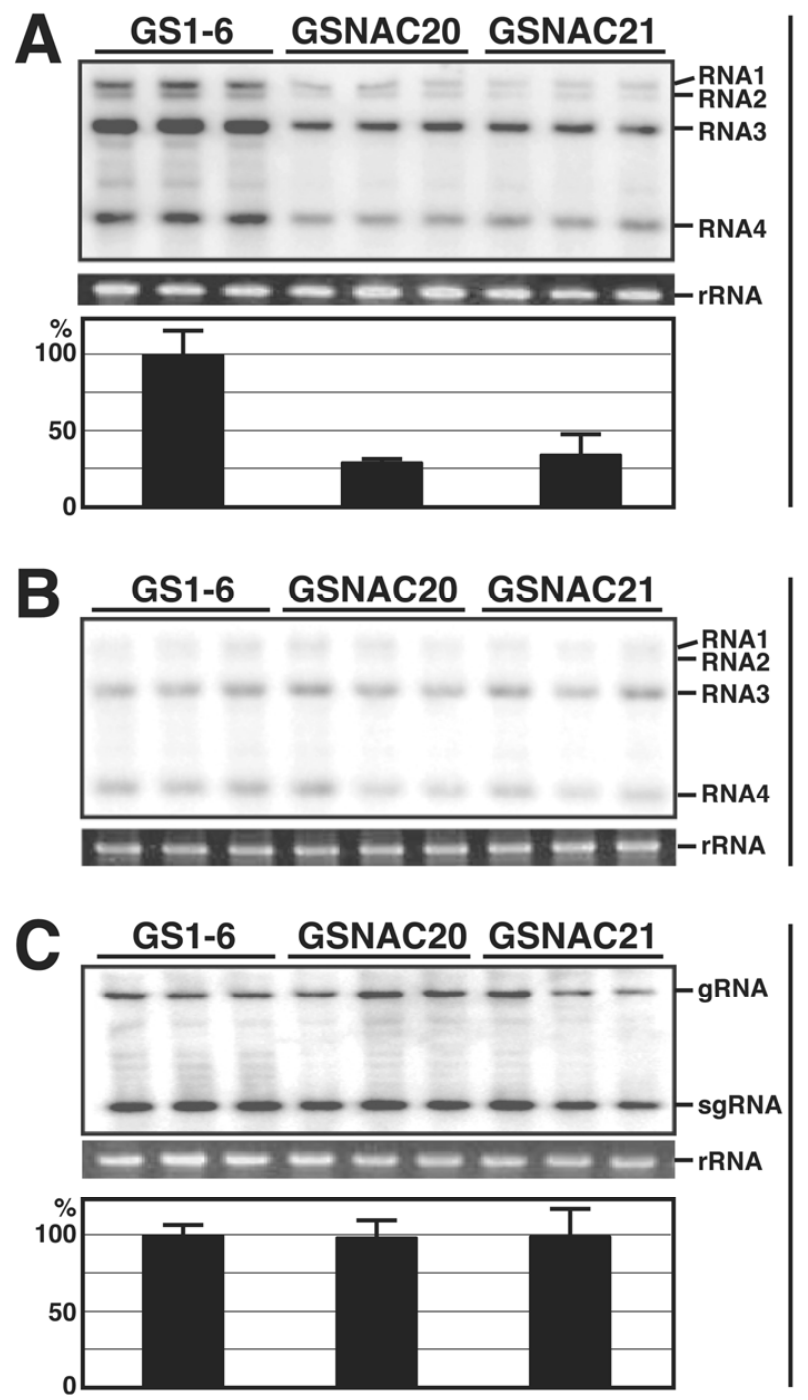

Fig. 4. Analysis of viral RNA accumulation in inoculated leaves of transgenic Nicotiana benthamiana. Three independent plants of GS1 plant line 6 and GSNAC plant lines 20 and 21 were used. A mixture of Agrobacterium cultures A, expressing wild-type Brome mosaic virus (BMV) RNAs or B, expressing wild-type RNA1 and wild-type RNA2 and frameshift mutant RNA3 from which movement protein (MP) is not translated was infiltrated into half-leaves of the plants. At 3 days postinfiltration (dpi), total RNA was extracted. The total RNA $(2 \mu \mathrm{g})$ was loaded in each lane and probed with a digoxigenin-labeled RNA probe complementary to the $3^{\prime}$ 200 nucleotides of the BMV RNAs. The intensity of the ethidium-bromidestained rRNA band indicates the relative amounts of sample loaded. The normalized levels of total BMV RNA accumulation relative to the amount of the internal standard (rRNA) were calculated. Summarized data from the repeated wild-type BMV multiplication assays are shown in the graph. Data are the averages \pm standard error (SE) of three replicates, each containing three half-leaves from independent plants. $\mathbf{C}$, Tomato mosaic virus (ToMV) virion $(20 \mu \mathrm{g} / \mathrm{ml})$ was mechanically inoculated and total RNA was extracted at $3 \mathrm{dpi}$. Total RNA ( $2 \mu \mathrm{g})$ was loaded in each lane and probed with a digoxigenin-labeled RNA probe complementary to the $3^{\prime}$ untranslated region of ToMV RNA. The intensity of the ethidium-bromidestained rRNA band indicates the relative amounts of sample loaded. The normalized levels of total ToMV RNA accumulation relative to the internal standard (rRNA) were calculated. Summarized data from the repeated ToMV multiplication assays are shown on the graph. Data are the averages \pm SE of three replicates, each containing three half-leaves from independent plants. acid residues near their N-termini. EGD2, the $\alpha$-NAC of Saccharomyces cerevisiae (accession number NP_012063), does not have an N-terminal acidic amino acid cluster and its similarity to $\mathrm{NbNACa} 1$ is as low as $46.8 \%$.

\section{BMV MP binds to NbNACa1 in vivo.}

Recombinant NbNACa1 protein tagged with six histidine residues was prepared in $E$. coli and then used to raise rabbit anti-NbNACal antiserum. Western blot analysis of the total
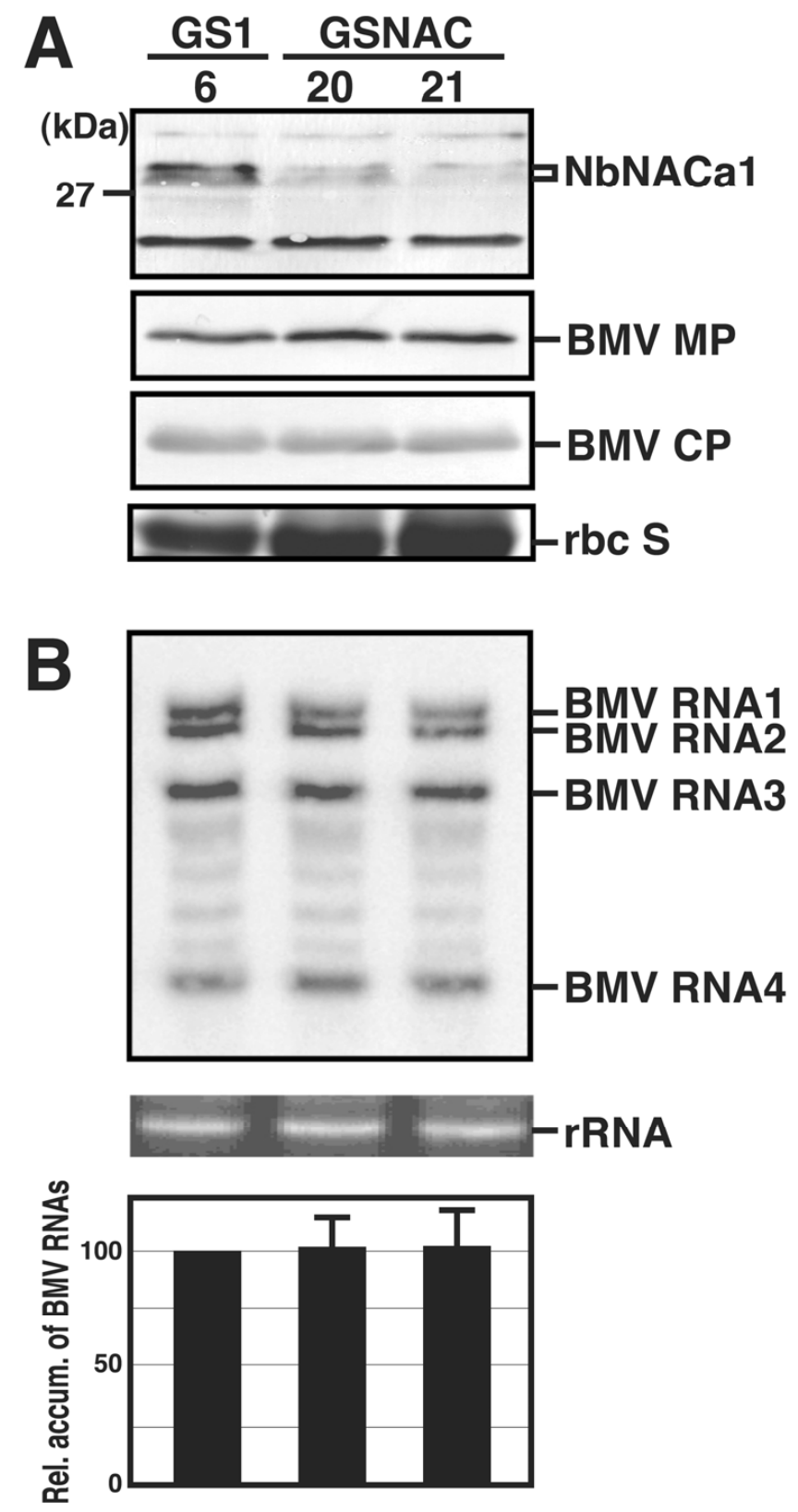

Fig. 5. Downregulation of $N b N A C a l$ expression does not affect the accumulation of Brome mosaic virus (BMV) RNAs or proteins in virus-inoculated protoplasts. In all, $1 \times 10^{6}$ protoplasts from GS1 or GSNAC plant lines 20 and 21 were inoculated with $2 \mu \mathrm{g}$ of BMV RNA and incubated at $25^{\circ} \mathrm{C}$ for 24 h. A, Detection of NbNACa1 (upper panel), BMV movement protein (MP) (second panel), and BMV coat protein (CP) (third panel) by Western blotting using rabbit antiserum directed against each protein. In all, $3 \times 10^{3}$ protoplasts were loaded in each lane. Molecular weight marker size is indicated to the left. B, Detection of BMV RNAs by Northern blotting. Total RNA $(2 \mu \mathrm{g})$ was loaded in each lane. Summarized data from the repeated BMV multiplication assays in protoplasts are shown on the graph. Data are the averages \pm standard error of three replicates, indicating the values for BMV RNA accumulation in GSNAC plants relative to those in GS1 plants. 
proteins extracted from $N$. benthamiana leaves using this antiserum detected several bands (Fig. 2, lower panel, left four lanes). Two bands showing similar mobility are probably NbNACa1-related because their intensities were reduced by the downregulation of the NbNACal gene (Fig. 3C). It is unclear whether the two bands represent distinct proteins or the same protein partially modified posttranslationally.

To confirm the binding of BMV MP to NbNACa1 in vivo, an immunoprecipitation assay was performed. $N$. benthamiana leaves infiltrated with Agrobacterium cultures containing BMV-MP-expressing plasmid (pBICB3a) or a control plasmid (pBICP35) were subjected to precipitation with antiserum directed against BMV MP or NbNACa1. Pre-immune antiserum did not precipitate either NbNACa1 or BMV MP (data not shown). BMV MP was precipitated with anti-NbNACa1 antiserum from the pBICB3a-infiltrated leaves (Fig. 2). Conversely, NbNACa1 was precipitated with anti-BMV MP antiserum from the pBICB3a-infiltrated leaves but not in the pBICP35-infiltrated leaves. These results show that NbNACa1 does not bind to anti-BMV MP antibody or Protein-A-Sepharose beads. Collectively, these results strongly suggest that BMV MP binds to NbNACa1 in vivo.

\section{Production of transgenic plants \\ in which the NbNACal gene is silenced.}

To determine whether the NbNACal gene product is involved in the multiplication of BMV, we produced transgenic $N$. benthamiana plants (GSNAC plants) expressing hairpin-loop-like double-stranded (ds)RNA of the $3^{\prime}$ half of the NbNACal gene. Regenerants were self fertilized and the kanamycin-resistant progeny of GSNAC plant lines 20 and 21, in which small interfering (si)RNA (a hallmark of RNA silencing) corresponding to NbNACal was detected (Fig. 3A), were used in the experiments described below. The levels of accumulated NbNACal mRNA in GSNAC plants were less than half those in GS1 plants (Fig. 3B). In addition to NbNACal mRNA, an extra, longer band was detected from GSNAC plants (Fig. 3B), probably representing hairpin-like dsRNA transcripts, judging from their size. Western blot analysis showed that the levels of accumulated NbNACa1 protein also were reduced in GSNAC plants to approximately $30 \%$ relative to those in GS1 plants (Fig. 3C).

GSNAC plants exhibited slightly yellow-colored mosaic symptoms in their expanded leaves but grew as large and as fast as the nontransgenic plants or the control GS1 plants (transformed with the vector pBEGS1) (data not shown). We could not rule out the possibility that a metabolic disorder in the GSNAC plants affected viral multiplication. However, several plant viruses, including Tomato mosaic virus (ToMV) (Fig. 4C), multiplied similarly in both the GS1 and GSNAC plants. Global protein expression levels seemed to be the same in both types of transgenic plants because Coomassie Brilliant Blue staining of a sodium dodecyl sulfate polyacrylamide gel electrophoresis (SDS-PAGE) gel, in which the total proteins from the same fresh weights of leaves had been loaded, showed indistinguishable concentrations and banding patterns (data not shown). Furthermore, levels of exogenous protein accumulation induced by agroinfiltration, discussed in the final paragraphs of this section, were similar in both transgenic plants. From these data, we infer that the GSNAC plants did not have a lethal metabolic disorder that affected viral multiplication.

\section{Downregulation of the $\mathrm{NbNACa1}$ gene reduces the efficiency of BMV multiplication in infected leaves but not in protoplasts.}

BMV multiplication in GSNAC plants was examined and compared with that in GS1 plants. We used an Agrobacteriuminfiltration method to inoculate BMV, because it is reliable and easy (Gopinath et al. 2005). In preliminary experiments, we found that seven times more BMV RNAs accumulated in nontransgenic $N$. benthamiana leaves infiltrated with Agrobacterium cultures (optical density at $600 \mathrm{~nm}\left[\mathrm{OD}_{600}\right]=0.008$ ) expressing wild-type (movement-competent) BMV than in those infiltrated with Agrobacterium cultures expressing MP-frameshift (movement-deficient) BMV at 3 days postinfiltration (dpi) (data not shown). The difference in the accumulation of BMV RNAs probably was due to the capacity for cell-to-cell movement, because both the wild-type and MP-frameshift BMV multiplies to similar levels in barley protoplasts (Takeda et al. 2004).

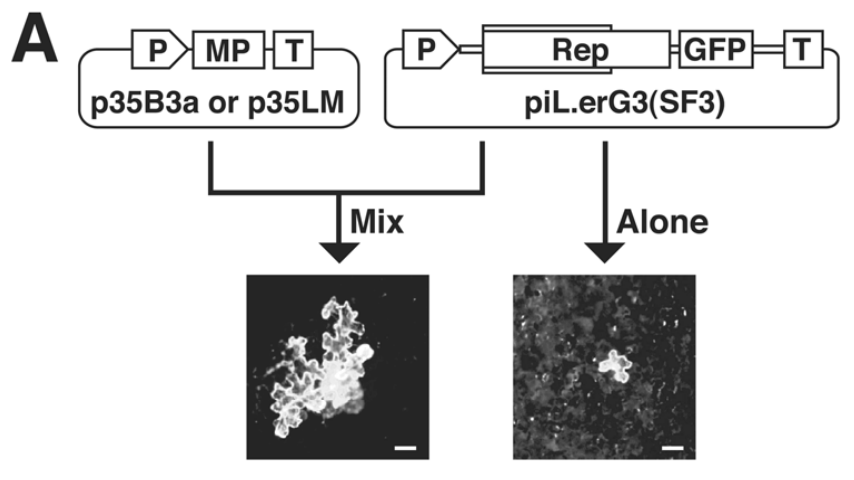

B

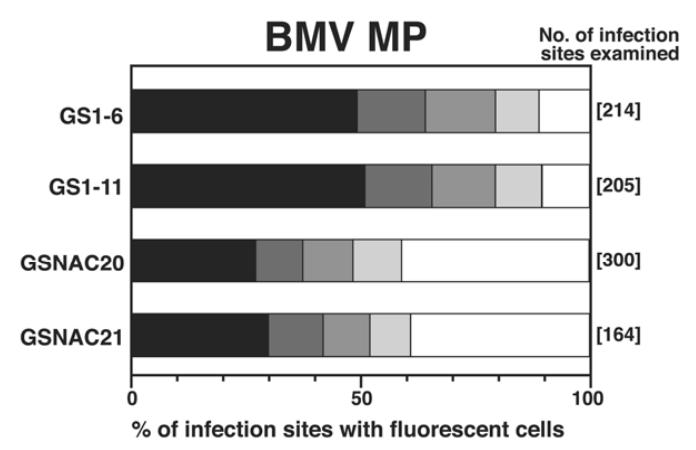

C

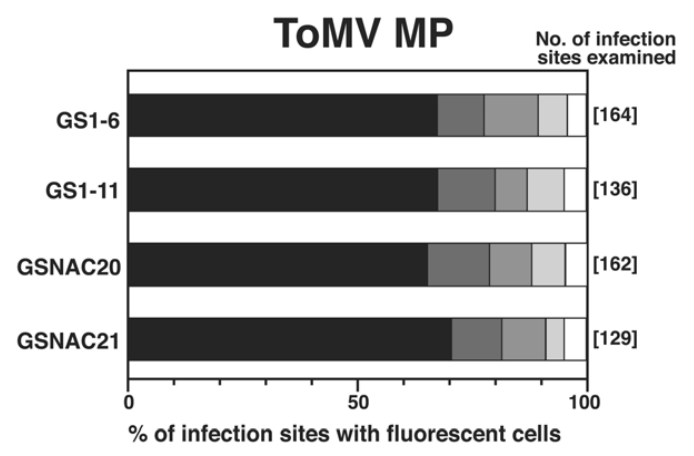

$\geq 5$ cells $\square 4$ cells $\square 3$ cells $\square 2$ cells $\square 1$ cell

Fig. 6. Brome mosaic virus (BMV) movement protein (MP) but not Tomato mosaic virus (ToMV) MP function is partially inhibited in GSNAC leaves. A, Schematic of the microprojectile bombardment assay and representative images of infection foci. Bars $=50 \mu \mathrm{m}$. piL.erG3(SF3) expressing chimeric ToMV, in which the MP and coat protein (CP) genes had been replaced with the gene for green fluorescent protein, was bombarded into transgenic Nicotiana benthamiana leaves together with B, p35B3a expressing BMV MP or $\mathbf{C}$, p35LM expressing ToMV MP. GS1 plant lines 6 and 11 and GSNAC plant lines 20 and 21 were used. At 2 days postbombardment, fluorescent foci were observed under an epifluorescence microscope. Data are the averages of six replicates, in each of which at least 40 fluorescent foci were counted. 
When half-leaves were infiltrated with wild-type BMV, the levels of viral RNAs accumulated at 3 dpi in the GS1 halfleaves were approximately threefold higher than those in the GSNAC half-leaves (Fig. 4A). Similar differences also were detected at 7 dpi (data not shown). By contrast, in the other half-leaves infiltrated with MP-frameshift BMV, viral RNAs accumulated to similar levels in both GS1 and GSNAC leaves (Fig. 4B), suggesting that BMV multiplied to similar levels in the initially infected cells.
To further investigate the multiplication levels of BMV RNAs in single cells, protoplasts were prepared from GSNAC and GS1 plants and inoculated with BMV. We confirmed that the accumulation of NbNACa1 protein in GSNAC protoplasts was substantially lower than that in GS1 protoplasts (Fig. 5A), The accumulation of BMV RNAs was similar in both GS1 and GSNAC protoplasts at $24 \mathrm{~h}$ postinoculation (hpi) (Fig. 5B). We also analyzed the accumulation of BMV MP and CP because they play crucial roles in the cell-to-cell movement of BMV.
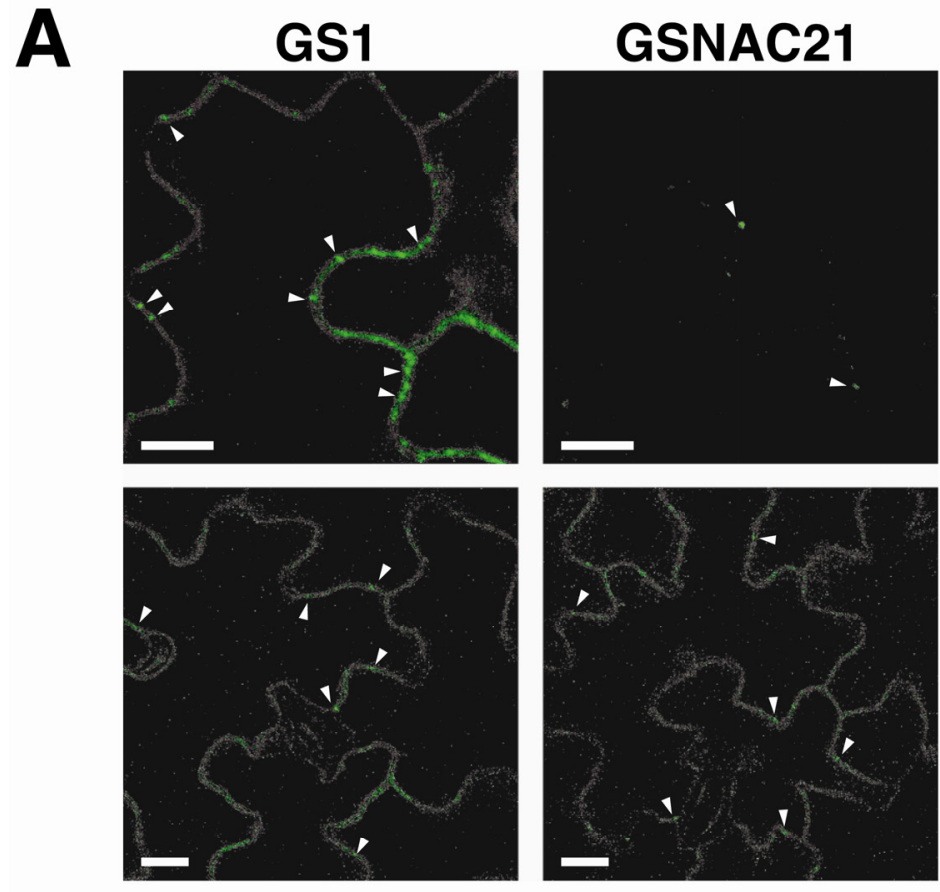

\section{0 hpi}

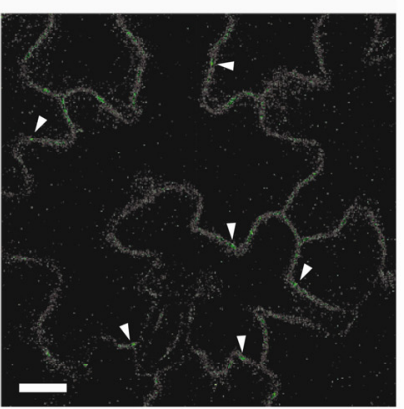

\section{$48 \mathrm{hpi}$}
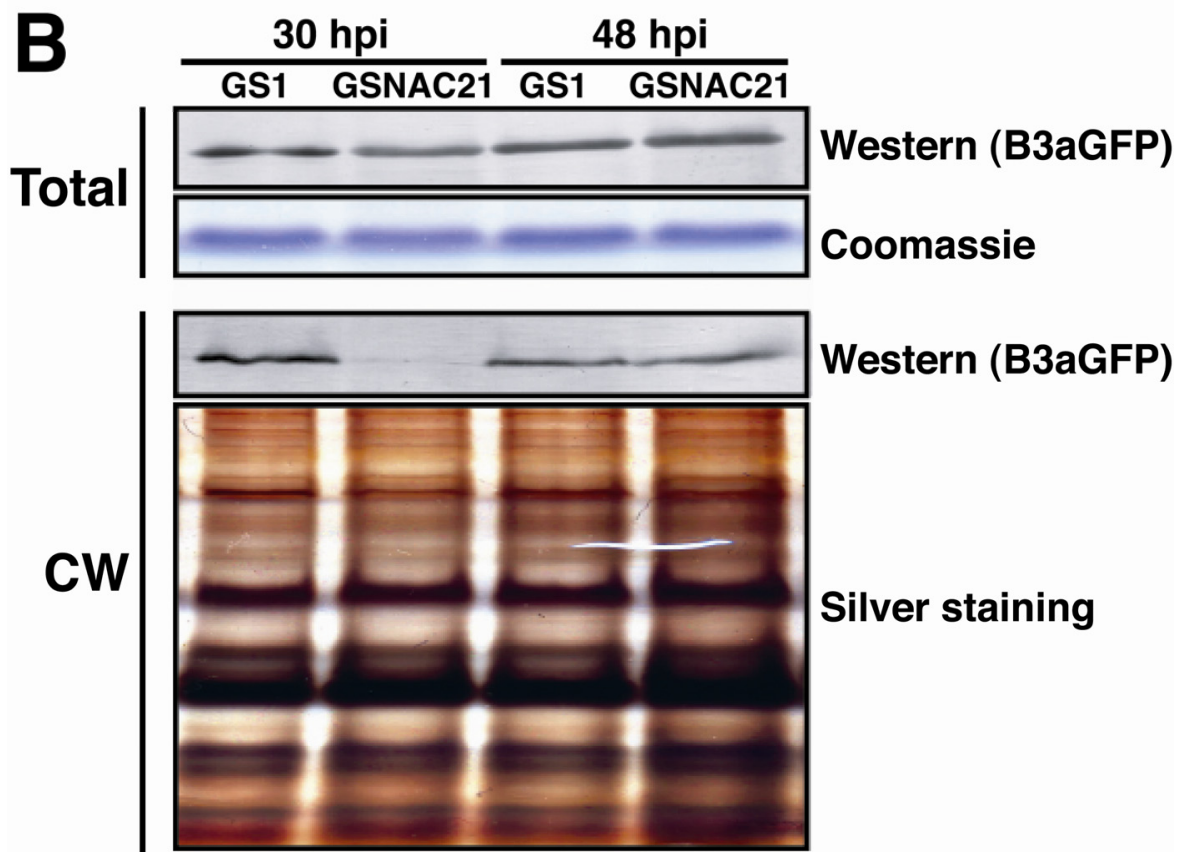

Fig. 7. Brome mosaic virus (BMV) movement protein-green fluorescent protein (MP-GFP) fusion protein localization was delayed in GSNAC leaves. An Agrobacterium culture expressing the BMV MP-GFP fusion protein was infiltrated into GS1 and GSNAC transgenic plants. At 30 and $48 \mathrm{~h}$ postinoculation (hpi), leaf samples were examined by confocal microscopy or subjected to protein extraction. A, GFP fluorescence spots (arrowheads) were detected using a confocal microscope with a $40 \times$ objective. Images are the projections of optical sections taken at $1-\mu \mathrm{m}$ intervals and were processed using Adobe Photoshop software. Bars $=20 \mu \mathrm{m}$. B, Total proteins and cell wall proteins were prepared from the Agrobacterium-infiltrated leaves and were subjected to sodium dodecyl sulfate polyacrylamide gel electrophoresis. BMV MP-GFP was detected by Western blot analysis using rabbit antiserum directed against BMV MP. Coomassie Brilliant Blue-stained band intensity of the small subunit of Rubisco (rbc S) and silver-stained band intensities of proteins in the cell wall fraction indicate the relative amounts of sample loaded. 
The amounts MP and CP accumulated were similar in GS1 and GSNAC protoplasts (Fig. 5A).

Overall, these results suggest that NbNACa1 is involved in the multiplication of BMV at the step after initial infection, probably during the cell-to-cell movement process. Similar levels of accumulation of MP and CP in both GSNAC and GS1 protoplasts suggest that NbNACa1 is not involved in the translational control or stability of these viral proteins but probably is directly involved in the viral movement process through its interaction with MP.

\section{Downregulation of the $N b N A C a 1$ gene reduces the efficiency of BMV cell-to-cell movement.}

Next, we used a microprojectile bombardment assay with epifluorescence microscopy to investigate the effects of the downregulation of $\mathrm{NbNACal}$ on the viral cell-to-cell movement mediated by BMV MP. A green fluorescent protein (GFP)-tagged ToMV genome lacking its own MP gene spread from initially bombarded $N$. benthamiana cells to neighboring cells by the function of the protein expressed from the cobombarded BMV MP gene (Fig. 6A) (Tamai et al. 2003). In GS1 plant leaves, approximately $90 \%$ of GFP fluorescent foci were composed of multiple cells and $10 \%$ were of single cells (Fig. $6 \mathrm{~B})$. This result is consistent with those of a previous study using nontransgenic $N$. benthamiana plants (Tamai et al. 2003). However, in GSNAC plants, approximately $60 \%$ of foci were composed of multiple cells and $40 \%$ were of single cells (Fig. $6 \mathrm{~B})$. That is, the occurrence of GFP fluorescent foci restricted to initially bombarded cells increased fourfold in GSNAC plants, suggesting that the function of BMV MP was partially inhibited by the suppression of NbNACal gene expression. These results strongly indicate that NbNACa1 protein supports or positively regulates BMV cell-to-cell movement.

\section{ToMV movement is not affected by the downregulation of the NbNACa1 gene.}

To investigate whether the downregulation of the NbNACal gene affects the multiplication of viruses other than BMV, we inoculated ToMV, which infects wild-type $N$. benthamiana plants systemically and induces severe symptoms. At 3 dpi, similar levels of ToMV RNAs had accumulated in the inoculated leaves of both GS1 and GSNAC plants (Fig. 4C). Moreover, the noninoculated upper leaves of both plants simultaneously turned yellow and the apical stems withered to death in 7 dpi (data not shown). These results indicate that the downregulation of the NbNACal gene does not affect ToMV multiplication. A microprojectile bombardment assay was used to investigate ToMV MP function in GS1 and GSNAC plants. In both plants, more than $94 \%$ of fluorescent foci were composed of multiple cells (Fig. 6C). These results show that ToMV movement functions are not affected by the downregulation of the NbNACal gene.

Other tobamoviruses, such as Youcai mosaic virus and Tobacco mild green mosaic virus, and Potato virus $X$, multiplied to similar levels in both GS1 and GSNAC plants (data not shown).

\section{Localization of BMV MP to the cell wall fraction is delayed in GSNAC plants.}

To investigate how NbNACa1 is involved in BMV cell-tocell movement, we examined the localization of a BMV MPGFP fusion protein in $N$. benthamiana leaves with confocal laser scanning microscopy. The pBICB3aGFP plasmid expressing the BMV MP-GFP fusion protein under the Cauliflower mosaic virus (CaMV) $35 \mathrm{~S}$ promoter was infiltrated via Agrobacterium tumefaciens into both GS1 and GSNAC leaves. At $30 \mathrm{hpi}$, many GFP fluorescent spots $\left(3,467\right.$ spots $\left./ \mathrm{mm}^{2}\right)$ were observed in the cell walls of GS1 epidermal cells, whereas lower densi- ties of GFP spots (338 spots $/ \mathrm{mm}^{2}$ ) were detected in GSNAC epidermal cells (Fig. 7A, upper panels). At 48 hpi, similar densities of GFP spots were detected in the cell walls of both GS1 $\left(2,470 \mathrm{spots} / \mathrm{mm}^{2}\right)$ and GSNAC $\left(2,580 \mathrm{spots} / \mathrm{mm}^{2}\right)$ epidermal cells (Fig. 7A, lower panels). No GFP fluorescent spots were detected in the cell walls before $24 \mathrm{hpi}$ or after $72 \mathrm{hpi}$ (data not shown).

The accumulation of the BMV MP-GFP fusion protein also was detected by Western blot analysis in the total and cell wall fractions of the agroinfiltrated leaves (Fig. 7B). Although GFP fluorescence was barely detected in GSNAC leaves at 30 hpi by confocal microscopy, similar amounts of BMV MP-GFP accumulated in the total protein of both GS1 and GSNAC leaves. In the cell wall fraction, BMV MP-GFP had accumulated much more in the GS1 leaves than in the GSNAC leaves at $30 \mathrm{hpi}$, as expected from the confocal microscopy results. At $48 \mathrm{hpi}$, similar levels of BMV MP-GFP had accumulated in the total and cell wall fractions of both types of transgenic plant leaves.

\section{DISCUSSION}

We have identified an in vivo interaction between BMV MP and the NbNACa1 protein of $N$. benthamiana in an immunoprecipitation assay (Fig. 2). From a BMV multiplication assay (Figs. 4 and 5) and a microprojectile bombardment assay (Fig. 6 ), and the localization analysis of a BMV MP-GFP fusion protein (Fig. 7), using transgenic $N$. benthamiana plants in which the NbNACal gene was silenced (Fig. 3), we propose that NbNACa1 is a host factor involved in the cell-to-cell movement of BMV through the regulation of the localization of MP to the PD. However, the downregulation of the NbNACal gene had no effect on ToMV multiplication (Figs. 4C and 6C), suggesting that the movement mechanism of ToMV is different from that of BMV. It would be interesting to determine whether there is a correlation between the infectivity of various viruses in GSNAC plants and the interaction of the MPs and NbNACa1.

NbNACa1 protein has high sequence similarity to the plant $\alpha$-NAC orthologs (Fig. 1). NAC was isolated first from the polysome fraction of bovine brain extract as a heterodimeric complex of $\alpha$ and $\beta$ chains and was identified as an element that interacts with newly synthesized polypeptides (Wiedman et al. 1994). The $\alpha$ - and $\beta$-NAC orthologs have been found in many eukaryotes. A number of functions of NAC proteins have been reported thus far from a variety of eukaryotes, although they remain controversial (Rospert et al. 2002). i) Several in vitro experiments have revealed $\alpha-\mathrm{NAC}$ as the negative regulator of the translocation of newly synthesized proteins without a signal peptide into the endoplasmic reticulum (ER) (Lauring et al. 1995a,b; Wiedman et al. 1994). ii) The yeast EGD2 gene, encoding an $\alpha$-NAC ortholog, was shown in vivo to positively regulate the translocation of mitochondrial protein to the ER and mitochondria (Fünfschilling and Rospert 1999; George et al. 1998). iii) Mammalian $\alpha-N A C$ functions as a developmentally regulated, bone-specific transcriptional coactivator (Moreau et al. 1998; Quélo et al. 2004a,b). iv) $\beta$-NAC of Caenorhabditis elegans is involved in the suppression of apoptosis, independent of CED-3 caspase (Bloss et al. 2003). Interestingly, human $\alpha$-NAC also may be involved in the suppression of cell death because it has the capacity to bind to and interfere with the function of Fas-associated protein with a death domain, which plays an important role in the cell death signal transduction pathway (Stilo et al. 2003). v) The mammalian $\alpha$-NAC protein is involved in the proliferation of $\mathrm{T}$ cells, which are constituents of the immune system (Al-Shanti et al. 2004; Endharti et al. 2005). 
In functions $\mathrm{i}$ and $\mathrm{ii}$, it is possible that the translocationregulating functions of $\alpha$-NAC have some effect on the BMV MP functions in intracellular trafficking, leading to the proper arrangement of MP localization and efficient viral movement. A transcriptional coactivator function, such as iii, might be affected by the binding of $\alpha$-NAC to BMV MP, resulting in a reduced level of expression of the host plant genes involved in the restriction of BMV movement. It is more difficult to consider $\alpha$-NAC functions iv and $\mathrm{v}$ in relation to BMV movement. No functional analysis of NAC in higher plants has been reported thus far. The elucidation of $\alpha$-NAC functions in higher plants may help us to propose a more plausible model of BMV movement in relation to $\alpha$-NAC. It also is possible that the interaction with BMV MP changes the natural function of $\mathrm{NAC}$, and that BMV may exploit that change.

A cell-to-cell movement function also has been found in endogenous plant non-cell-autonomous-pathway proteins. For example, Cmpp16 protein extracted from the phloem tissue of pumpkin reacted with monoclonal antibody raised against MP of Red clover necrotic mosaic virus and had functions similar to those of the plant virus MP, such as increasing the size exclusion limit of the PD and binding to and trafficking singlestranded RNA to neighboring cells (Xoconostle-Cázares et al. 1999). Lee and associates (2003) reported that a binding partner of Cmpp16 protein in tobacco plants, NtNCAPP1, localizes at the outer surface of the ER membrane and affects Cmpp16 and TMV MP functions to increase the size exclusion limit. Interestingly, NtNCAPP1 did not affect the SEL-increasing ability of Cucumber mosaic virus MP or that of another plant non-cell-autonomous-pathway protein, KNOTTED1. The authors suggested that NtNCAPP1 could function to shuttle plant non-cell-autonomous-pathway proteins and virus MPs to the plasmodesmal microchannels (Lee et al. 2003). The binding ability of NbNACa1 to BMV MP and its involvement in cell-to-cell movement in a virus-specific manner may imply that NbNACa1 has a shuttle function similar to that of NtNCAPP1. It will be interesting to test the correlation between the binding specificity of NbNACa1-viral MPs and the involvement of NbNACa1 in viral movement. Further investigation of the localization of NbNACa1 should shed light on the protein's function in viral movement.

To date, two examples of an interaction between $\alpha$-NAC and viral proteins have been reported, although the involvement of $\alpha$-NACs in the multiplication of those viruses has not been clarified. The protein $\mathrm{j} 4 \mathrm{R}$, the function of which is unknown, is encoded by African swine fever virus (ASFV) of the Poxviridae family, and has been shown to interact both in vitro and in vivo with human $\alpha-N A C$ (accession number X80909) (Goatley et al. 2002), which has $64.7 \%$ similarity to NbNACa1 (data not shown). The protein colocalizes at the plasma membrane with $\alpha$-NAC. Another example is the preS1 protein of Human hepatitis B virus (HBV) belonging to the Hepadnaviridae family (Li et al. 2005). PreS1 constitutes the outer membrane of HBV and is essential for virus assembly and infectivity. PreS1 binds to human $\alpha$-NAC in vitro and monkey $\alpha$-NAC in vivo. It is possible that the binding partner of the viral outer-membrane protein functions as a cellular receptor or an intracellular trafficking cargo to secrete the virus. The latter function is analogous to the putative NbNACal function in BMV MP localization.

In the yeast knockout mutant egd2, which lacks the $N b N A C a l$ ortholog EGD2, luciferase activity was monitored in a BMVreplication-dependent manner and was shown to be reduced to $73.4 \%$ of that in wild-type yeast (Kushner et al. 2003). This is in contrast to the results of our protoplast experiments (Fig. 5B), which showed similar levels of BMV RNA accumulation regardless of the downregulation of $N b N A C a l$ expression at the single-cell level. In GSNAC plants, the silencing of the NbNACal gene is incomplete (Figs. 3B and 5A) and the residual NbNACal gene expression might have contributed to BMV multiplication at the single-cell level. Alternatively, the two $\alpha$-NAC orthologs may have distinct functions and contribute to BMV multiplication at different steps, because their similarity is as low as $46.8 \%$. In particular, EGD2 lacks the N-terminal cluster of acidic amino acid residues that is characteristic of the $\alpha$ NACs of higher plants (Fig. 1).

\section{MATERIALS AND METHODS}

\section{Far-Western screening.}

An NheI site, a five-glycine spacer sequence, and a six-histidine tag sequence were introduced just before the termination codon of the BMV MP gene of pB3TP10 (Pacha and Ahlquist 1991 ) by polymerase chain reaction (PCR) mutagenesis, to create pB3B3aNheG5H6. A consensus phosphorylation sequence for protein kinase A, encoding Arg-Arg-Ala-Ser-Val (Matsushita et al. 2001), was introduced into the NheI site of pB3B3aNheG5H6, creating pB3B3aHMKG5H6. This construct was cut with BamHI, treated with T4 DNA polymerase, and cut with $B g l \mathrm{II}$. The resulting 0.9-kb fragment was introduced into pET-42a(+) (Novagen, Madison, WI, U.S.A.) that had been cut with SpeI, treated with T4 DNA polymerase, and cut with $B g l$ II, creating pGST-B3aHMKG5H6.

pGST-B3aHMKG5H6 was introduced into $E$. coli BL21(DE3) (Novagen) and the expression of GST-fused BMV MP (GST-B3aHMKG5H6) was induced with isopropyl- $\beta$-Dthiogalactopyranoside (IPTG). After the E. coli cells were disrupted with sonication, GST-B3aHMKG5H6 protein was precipitated with Glutathione Sepharose 4B resin (GE Healthcare Bio-Science Corp., Piscataway, NJ, U.S.A.) and labeled directly with $\left[\gamma^{32} \mathrm{P}\right]$ ATP with bovine protein kinase A (SigmaAldrich, St Louis). The ${ }^{32} \mathrm{P}$-labeled GST-fused protein was purified and recovered as described previously (Okinaka et al. 2003).

Far-Western screening of an $N$. benthamiana cDNA library was performed as described (Matsushita et al. 2001), with minor modifications. Poly(A) ${ }^{+}$RNA was purified using the BioMag Oligo(d)T kit (Perspective Biosystems, Cambridge, MA, U.S.A.) from total RNA that was extracted from fully expanded leaves of $N$. benthamiana at the seven-leaf stage. Doublestranded cDNA was synthesized from the poly $(\mathrm{A})^{+}$RNA with oligo(dT) primer using the SuperScript Choice System for cDNA Synthesis (Gibco BRL, Gaithersburg, MD, U.S.A.), and ligated with an SfiI adapter (Fukunaga and Hunter 1997). The size-fractionated cDNA was ligated to SfiI-digested $\lambda$ GEX5 phage (Fukunaga and Hunter 1997). The N. benthamiana cDNA expression library thus obtained was plated on E. coli BB4 strain at a density of $1.0 \times 10^{4}$ plaques per $180-\mathrm{cm}^{2} \mathrm{LB}$ agar plate. The resultant plaques were transferred to Hybond $\mathrm{C}^{+}$nitrocellulose membrane filters (GE Healthcare Bio-Science Corp.) that had been immersed in $10 \mathrm{mM}$ IPTG and air dried to induce the expression of GST fusion proteins. The membranes were peeled off and treated with washing solution $1(10 \mathrm{mM}$ Tris- $\mathrm{HCl}[\mathrm{pH}$ 7.5], $15 \mathrm{mM} \mathrm{NaCl}, 0.1 \%$ [vol/vol] Tween 20) for $5 \mathrm{~min}$, and then with blocking solution $(140 \mathrm{mM} \mathrm{NaCl}, 2.7 \mathrm{mM} \mathrm{KCl}, 10$

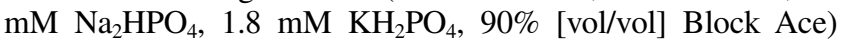
(Dai-Nihon Seiyaku Co., Tokyo) at room temperature for $1 \mathrm{~h}$. ${ }^{32}$ P-labeled GST-B3aHMKG5H6 was added to the blocking solution at a final concentration of $2 \times 10^{5} \mathrm{cpm} / \mathrm{ml}$ and incubated at $4^{\circ} \mathrm{C}$ for $10 \mathrm{~h}$. The membranes then were washed four times for $5 \mathrm{~min}$ each with washing solution $2(137 \mathrm{mM} \mathrm{NaCl}, 2.6 \mathrm{mM}$ $\mathrm{KCl}, 10 \mathrm{mM} \mathrm{Na} 2 \mathrm{HPO}_{4}, 1.8 \mathrm{mM} \mathrm{KH}_{2} \mathrm{PO}_{4}, 0.2 \%$ [vol/vol] Triton $\mathrm{X}-100$ [pH 7.4]), and subjected to autoradiography on the Fujix BAS2000 system (Fuji Photo Film, Tokyo). 
Immunoprecipitation assays.

The PCR-amplified BMV MP gene was subcloned between the CaMV 35S promoter and terminator of the pBICP35 binary vector plasmid (Mori et al. 1992), creating pBICB3a. pBICP35 or pBICB3a was introduced into Agrobacterium tumefaciens $\mathrm{C}$ 8C1Rif ${ }^{\mathrm{R}}$ containing $\mathrm{pMP} 90$ and incubated, as described previously (Llave et al. 2000), with the appropriate antibiotics. This Agrobacterium strain was used throughout this study. Agrobacterium cultures were incubated overnight, and then, were washed and suspended in $10 \mathrm{mM} \mathrm{MgSO}_{4}$ to $\mathrm{OD}_{600}=0.8$, and infiltrated into the youngest fully expanded leaf of 7- to 8week-old transgenic $N$. benthamiana plants. At $2 \mathrm{dpi}$, the leaves were subjected to an immunoprecipitation assay as described by Kurihara and associates (2006), with minor modifications. Briefly, $2 \mathrm{~g}$ of agroinfiltrated leaves were ground in 6 $\mathrm{ml}$ of extraction buffer $(50 \mathrm{mM}$ Tris- $\mathrm{HCl}$ [pH 8.0], $150 \mathrm{mM}$ $\mathrm{NaCl}, 5 \%$ glycerol, $0.2 \% \beta$-mercaptoethanol, $0.5 \%$ Triton $\mathrm{X}$ $100,1 \times$ complete protease inhibitor cocktail [Roche Molecular Biochemicals, Indianapolis, IN, U.S.A.]) and centrifuged at $18,000 \times g$ for $10 \mathrm{~min}$. An aliquot $(3 \mathrm{ml})$ of the supernatant was mixed with $50 \mu$ l of Protein-A-Sepharose beads (GE Healthcare Bio-Science Corp.) equilibrated with the extraction buffer and $15 \mu \mathrm{l}$ of rabbit polyclonal antiserum directed against BMV MP or NbNACa1 and incubated with gentle rotation at $4^{\circ} \mathrm{C}$ for $4 \mathrm{~h}$. The beads were washed three times with washing buffer (50 mM Tris- $\mathrm{HCl}$ [pH 7.4], $150 \mathrm{mM} \mathrm{NaCl}, 5 \%$ glycerol, $0.1 \%$ Triton $\mathrm{X}-100)$ and the precipitated proteins were extracted in $100 \mu \mathrm{l}$ of Laemmli buffer (Laemmli 1970). After the samples had been boiled for $2 \mathrm{~min}, 20 \mu \mathrm{l}$ of each sample was subjected to SDS-PAGE and, subsequently, to Western blot analysis.

\section{Production of transgenic $N$. benthamiana plants.}

A GUS fragment of approximately $1 \mathrm{~kb}$ (nucleotides 783 to 1786 from the start codon) was amplified by PCR using the primers Mkdouble1 (5'-GGGTACGTAATTTAAATAGTACTC CTGCAGGGTGTGATATCTACCCGCTTCGCGTC-3'; the underlined bases encode SnaBI, SwaI, ScaI, and Sse8387I sites) and Mkdouble2 (5'-CGCGGATCCCT CGAGACTAGTGGCG CGCCCTTTTTCACCGAAGTTCATGCCAGTC-3'; the underlined bases encode BamHI, XhoI, SpeI, and AscI sites). The fragment was digested with $S n a \mathrm{BI}$ and $B a m \mathrm{HI}$, and ligated into the SnaBI/BamHI sites of pBE2113 (Mitsuhara et al. 1996), creating pBEGS1. The NbNACal fragment in the pGEX5 plasmid was amplified using the primers MKdouble3 (5'-CCGCCGCCT GCAGGCTGGTTCCGCGTGGATCCCC-3') and MKdouble4 (5'-CCGGGCATTTAAATGGCCGCAAGCTTAGTCAT-3'), or primers MKdouble5 (5'-CCGGCGCGCCCTGGTTCCGCGT GGATCCCC-3') and MKdouble6 (5'-GGTCATCTCGAGGGC CGCAAGCTTAGTCAT-3'). Each fragment was digested with SwaI and Sse8387I or AscI and XhoI, respectively, and introduced into the $S w a \mathrm{I} / S s e 8387 \mathrm{I}$ and $A s c \mathrm{I} / \mathrm{XhoI}$ sites of pBEGS1, respectively, creating pBEGSNAC. pBEGS1 and pBEGSNAC were introduced into $A$. tumefaciens and used to transform the young stems of 7- to 8-day-old $N$. benthamiana, as described previously (Horsch et al. 1985). Transgenic plants were selected on medium containing kanamycin $(50 \mu \mathrm{g} / \mathrm{ml})$ and were grown in commercially available soil mixtures in a plant growth room at $25^{\circ} \mathrm{C}$ with illumination for $16 \mathrm{~h}$ per day.

\section{Virus inoculation and RNA analysis.}

pBICBR1R, pBICBR2R, and pBICBR3R are binary vectors expressing genomic RNA1, RNA2, and RNA3, respectively, of the BMV KU1 strain (Kaido et al. 1997). The cDNA inserts of the vectors were replaced precisely with the corresponding cDNAs of the BMV M1 strain (Janda et al. 1987) and used in this study. The binary vector pBICBR3fsMP was constructed to express a mutant RNA3 of the BMV M1 strain from which 3a MP is not expressed (Takeda et al. 2004). These plasmids were introduced into A. tumefaciens and incubated as described previously (Llave et al. 2000). Before infiltration, Agrobacterium cells were suspended in $10 \mathrm{mM} \mathrm{MgCl}$ to an $\mathrm{OD}_{600}$ of 0.008 and mixed by combining equal volumes of individual cultures $\left(\mathrm{OD}_{600}=0.008\right.$ for each Agrobacterium $)$. A mixed suspension of $A$. tumefaciens carrying pBICBR1R, pBICBR2R, and pBICBR3R (wild-type BMV M1) or pBICBR1R, pBICBR2R, and pBICBR3fsMP (MP-frameshift mutant of BMV M1) was infiltrated into the youngest fully expanded half-leaves of 7- to 8-week-old transgenic $N$. benthamiana plants. Total RNA was extracted from the patches on the infiltrated leaves using Plant RNA Purification Reagent (Invitrogen, Carlsbad, CA, U.S.A.). The preparation of protoplasts from transgenic $N$. benthamiana, the inoculation of BMV RNA, and the extraction of total RNA were as described previously (Mizumoto et al. 2002).

Northern blot analysis using digoxigenin-labeled RNA probes (Roche Molecular Biochemicals) was as described previously (Mizumoto et al. 2002). pBSPL10 (Mori et al. 1992) was used for the transcription of a probe to detect BMV positive-strand RNA. pBKSL3' plasmid containing the $3^{\prime}$ untranslated region of ToMV was used for the transcription of a probe to detect ToMV positive-strand RNA (Morishima et al. 2003). The template DNA for the detection of $N b N A C a l$ mRNA was constructed as follows. A 634-nucleotide NbNACal sequence in $\lambda$ GEX5 phage DNA was PCR amplified using primers MKdouble5 and MKdouble6. The fragment was digested with BamHI and XhoI, and introduced into the BamHI/XhoI sites of pBluescript KS(+) (Stratagene, La Jolla, CA, U.S.A.). The resultant plasmid, pBSP1, was digested with BamHI and the probe RNA was transcribed with T3 RNA polymerase.

The RNA signals were detected with a luminescent-image analyzer (LAS 1000 Plus; Fuji Photo Film, Japan), and the signal intensities were quantified with the Image Gauge program (Fuji Photo Film).

siRNAs of NbNACal were detected as described previously (Hamilton and Baulcombe 1999) using ${ }^{32}$ P-labeled pBSP1 transcripts as the probe.

\section{Microprojectile bombardment assay.}

The microprojectile bombardment assay was performed with a PDS1000 helium particle gun (Bio-Rad Laboratories, Hercules, CA, U.S.A.) using the plasmids and conditions described previously (Tamai and Meshi 2001; Tamai et al. 2003).

\section{Localization of BMV MP-GFP fusion protein.}

The binary vector pBICB3aGFP, which expresses the fusion protein BMV MP-GFP, was constructed as follows. pB3B3aGFPG5H6 (Y. Inoue and K. Mise, unpublished) is a plasmid containing a gene encoding BMV MP-ASISG 4 wildtype $\mathrm{GFP}-\mathrm{ASG}_{5} \mathrm{H}_{6}$, where $\mathrm{ASISG}_{4}$ and $\mathrm{ASG}_{5} \mathrm{H}_{6}$ represent amino acid residues and their copy numbers. After a point mutation (serine 65 to threonine) was introduced into the wildtype gene for GFP (Chalfie et al. 1994), the gene for BMV MP-GFP was PCR amplified using the Bam/B3a5' primer $\left(5^{\prime}\right.$ GGGGGGATCCATGTCTAACATAGTTTCT-3') and the Bam/ GFP3' primer (5'-GGGGGGATCCTTATTTGTATAGTTCATC C-3'), the underlined bases of which contain the BamHI restriction endonuclease site. The fragment was cut with BamHI and introduced into the BamHI site of pBICP35 (Mori et al. 1992), creating pBICB3aGFP.

pBICB3aGFP was introduced into A. tumefaciens. Agroinfiltration into $N$. benthamiana leaves was as described above. The cell wall fraction of $N$. benthamiana was prepared as described previously (Fujita et al. 1998) and the proteins in the 
fraction were extracted with buffer containing $6 \mathrm{M}$ urea (Erny et al. 1992). Total proteins were extracted with Laemmli buffer (Laemmli 1970). The proteins were subjected to SDS-PAGE, and BMV MP-GFP was detected by Western blot analysis using rabbit antiserum directed against BMV MP. GFP fluorescence was detected using an Olympus Fluoview FV500 confocal microscope with a 40x UPlanApo oil-immersion objective. All fluorescent images are projections of optical sections taken at $1-\mu \mathrm{m}$ intervals, and were processed using Adobe Photoshop 7.0 software.

\section{ACKNOWLEDGMENTS}

We thank P. Ahlquist for the cDNA clones of BMV M1 strain and R. Fukunaga for $\lambda$ GEX5. We also thank H. Nyunoya, Y. Matushita, and A. Mine for technical assistance. This work was supported in part by a Grant-inAid (17780035) for Young Scientist B, a Grant-in-Aid (15380035 and 17380029) for Scientific Research B, a Grant-in-Aid (13306005) for Scientific Research A from the Japan Society for the Promotion of Science, and a Grant-in-Aid (12052201) for Scientific Research on Priority Area (A) from the Ministry of Education, Culture, Sports, Science and Technology, Japan.

\section{LITERATURE CITED}

Al-Shanti, N., Steward, C., Garland, R., and Rowbottom, A. 2004. Investigation of alpha nascent polypeptide-associated complex functions in a human $\mathrm{CD}^{+} \mathrm{T}$ cell ex vivo expansion model using antisense oligonucleotides. Immunology 112:397-403.

Ashby, J., Boutant, E., Seemanpillai, M., Sambade, A., Ritzenthaler, C., and Heinlein, M. 2006. Tobacco mosaic virus movement protein functions as a structural microtubule-associated protein. J. Virol. 80:83298344.

Bloss, T., Witze, E., and Rothman J. 2003. Suppression of CED-3-independent apoptosis by mitochondrial BNAC in Caenorhabditis elegans. Nature 424:1066-1071.

Chalfie, M., Tu, Y., Euskirchen, G., Ward, W. W., and Prasher, D. C. 1994. Green fluorescent protein as a marker for gene expression. Science 263:802-805.

Chen, M. H., and Citovsky, V. 2003. Systemic movement of a tobamovirus requires host cell pectin methylesterase. Plant J. 35:386-392.

Chen, M. H., Sheng, J. S., Hind, G., Handa, A. K., and Citovsky, V. 2000. Interaction between the Tobacco mosaic virus movement protein and host cell pectin methylesterase is required for viral cell-to-cell movement. EMBO (Eur. Mol. Biol. Organ.) J. 19:913-920.

Chen, M. H., Tian, G. W., Gafni, Y., and Citovsky, V. 2005. Effects of calreticulin on viral cell-to-cell movement. Plant Physiol. 138:1866-1876.

Dohi, K., Mori, M., Furusawa, I., Mise, K., and Okuno, T. 2001. Brome mosaic virus replicase proteins localize with the movement protein at infection-specific cytoplasmic inclusions in infected barley leaf cells. Arch. Virol. 146:1607-1615.

Dorokhov, Y. L., Makinen, K., Frolova, O. Y., Merits, A., Saarinen, J., Kalkkinen, N., Atabekov, J. G., and Saarma, M. A. 1999. Novel function for a ubiquitous plant enzyme pectin methylesterase: the host-cell receptor for the Tobacco mosaic virus movement protein. FEBS (Fed. Eur. Biochem. Soc.) Lett. 461:223-228.

Endharti, A., Zhou, Y., Nakashima, I., and Suzuki, H. 2005. Galectin-1 supports survival of naive $\mathrm{T}$ cells without promoting cell proliferation. Eur. J. Immunol. 35:86-97.

Erny, C., Schoumacher, F., Jung, C., Gagey, M. J., Godefroy-Colburn, T., Stussi-Garaud, C., and Berna, A. 1992. An N-proximal sequence of the Alfalfa mosaic virus movement protein is necessary for association with cell walls in transgenic plants. J. Gen. Virol. 73:2115-2119.

Fujita, M., Mise, K., Kajiura, Y., Dohi, K., and Furusawa, I. 1998. Nucleic acid binding properties and subcellular localization of the $3 \mathrm{a}$ protein of Brome mosaic bromovirus. J. Gen. Virol. 79:1273-1280.

Fukunaga, R., and Hunter, T. 1997. MNK1, a new MAP kinase-activated protein kinase, isolated by a novel expression screening method for identifying protein kinase substrates. EMBO (Eur. Mol. Biol. Organ.) J. 16:1921-1933.

Fünfschilling, U., and Rospert, S. 1999. Nascent polypeptide-associated complex stimulates protein import into yeast mitochondria. Mol. Biol. Cell 10:3289-3299.

George, R., Beddoe, T., Landl, K., and Lithgow, T. 1998. The yeast nascent polypeptide-associated complex initiates protein targeting to mitochondria in vivo. Proc. Natl. Acad. Sci. U.S.A. 95:2296-2301.

Goatley, L. C., Twigg, S. R. F., Miskin, J. E., Monaghan, P., St-Arnaud, R.,
Smith, G. L., and Dixon, L. K. 2002. The African swine fever virus protein $\mathrm{j} 4 \mathrm{R}$ binds to the alpha chain of nascent polypeptide-associated complex. J. Virol. 76:9991-9999.

Gopinath, K., Dragnea, B., and Kao, C. 2005. Interaction between Brome mosaic virus proteins and RNAs: effects on RNA replication, protein expression, and RNA stability. J. Virol. 79:14222-14234.

Hamilton, A., and Baulcombe, D. C. 1999. A species of small antisense RNA in post-transcriptional gene silencing in plants. Science 286:950952.

Horsch, R. B., Fry, J. E., Hoffman, N. L., Eichholtz, D., Rogers, S. G., and Fraley, R. T. 1985. A simple and general method for transferring genes into plants. Science 227:1229-1231.

Janda, M. French, R., and Ahlquist, P. 1987. High efficiency T7 polymerase synthesis of infectious RNA from cloned Brome mosaic virus cDNA and effects of $5^{\prime}$ extensions on transcript infectivity. Virology 158:259-262.

Kaido, M., Mori, M., Mise, K., Okuno, T., and Furusawa, I. 1997. Autocleavable ribozyme sequence attached to Brome mosaic virus cDNAs enhances accumulation of viral RNAs transcribed in vivo from the cDNAs. Ann. Phytopathol. Soc. Jpn. 63:95-98.

Kim, J., Yuan, Z., and Jackson, D. 2003. Developmental regulation and significance of KNOX protein trafficking in Arabidopsis. Development 130:4351-4362.

Kragler, F., Curin, M., Trutnyeva, K., Gansch, A., and Waigmann, E. 2003. MPB2C, a microtubule-associated plant protein binds to and interferes with cell-to-cell transport of Tobacco mosaic virus movement protein Plant Physiol. 132:1870-1883.

Kurihara, Y., Yuasa, T., and Watanabe, Y. 2006. The interaction between DCL1 and HYL1 is important for efficient and precise processing of pri-miRNA in plant microRNA biogenesis. RNA 12:206-212.

Kushner, D., Lindenbach, B., Grdzelishvili, V., Noueiry, A., Paul, S., and Ahlquist, P. 2003. Systematic, genome-wide identification of host genes affecting replication of a positive-strand RNA virus. Proc. Natl. Acad. Sci. U.S.A. 100:15764-15769.

Laemmli, U. K. 1970. Cleavage of structural proteins during the assembly of the head of bacteriophage T4. Nature 227:680-685.

Lauring, B., Kreibich, G., and Wiedmann, M. 1995a. The intrinsic ability of ribosomes to bind to endoplasmic reticulum membranes is regulated by signal recognition particle and nascent-polypeptide-associated complex. Proc. Natl. Acad. Sci. U.S.A. 92:9435-9439.

Lauring, B., Sakai, H., Kreibich, G., and Wiedmann, M. 1995b. Nascent polypeptide-associated complex protein prevents mistargeting of nascent chains to the endoplasmic reticulum. Proc. Natl. Acad. Sci. U.S.A. 92:5411-5415.

Lazarowitz, S. G., and Beachy, R. N. 1999. Viral movement proteins as probes for intracellular and intercellular trafficking in plants. Plant Cell 11:535-548.

Lee, J, Yoo, B., Rojas, M., Gomez-Ospina, N., Staehelin, L., and Lucas, W. 2003. Selective trafficking of non-cell-autonomous proteins mediated by NtNCAPP1. Science 299:392-396.

Li, D., Wang, X., Ding, J., and Yu J. 2005. NACA as a potential cellular target of Hepatitis B virus preS1 protein. Dig. Dis. Sci. 50:1156-1160.

Llave, C. Kasschau, K. D., and Carrington, J. C. 2000. Virus-encoded suppressor of posttranscriptional gene silencing targets a maintenance step in the silencing pathway. Proc. Natl. Acad. Sci. U.S.A. 97:13401-13406.

Lucas, W. J. 2006. Plant viral movement proteins: Agents for cell-to-cell trafficking of viral genomes. Virology 344:169-184.

Lucas, W. J., Bouche-Pillon, S., Jackson, D. P., Nguyen, L., Ding, B., and Hake, S. 1995. Selective trafficking of KNOTTED1 homeodomain protein and its messenger RNA through plasmodesmata. Science 270:1980-1983.

Matsushita, Y., Deguchi, M., Youda, M., Nishiguchi, M., and Nyunoya, H. 2001. The Tomato mosaic tobamovirus movement protein interacts with a putative transcriptional coactivator KELP. Mol. Cells 12:57-66.

McLean, B., Hempel, F., and Zambryski, P. 1997. Plant intercellular communication via plasmodesmata. Plant Cell 9:1043-1054.

Melcher, U. 2000. The ' $30 \mathrm{~K}$ ' superfamily of viral movement proteins. J. Gen. Virol. 81:257-266.

Mise, K., Allison, R. F., Janda, M., and Ahlquist, P. 1993. Bromovirus movement protein genes play a crucial role in host specificity. J. Virol. 67:2815-23.

Mitsuhara, I., Ugaki, M., Hirochika, H., Ohshima, M., Murakami, T., Gotoh, Y., Katayose, Y., Nakamura, S., Honkura, R., Nishimiya, S., Ueno, K., Mochizuki, A., Tanimoto, H., Tsugawa, H., Otuki, Y., and Ohashi, Y. 1996. Efficient promoter cassettes for enhanced expression of foreign genes in dicotyledonous and monocotyledonous plants. Plant Cell Physiol. 37:49-59.

Mizumoto, H., Hikichi, Y., and Okuno, T. 2002. The 3'-untranslated region of RNA1 as a primary determinant of temperature sensitivity of Red clover necrotic mosaic virus Canadian strain. Virology 293:320-327. 
Moreau, A., Yotov, W., Glorieux, F., and St-Arnaud, R. 1998. Bone-specific expression of the alpha chain of the nascent polypeptide-associated complex, a coactivator potentiating c-Jun-mediated transcription. Mol. Cell. Biol. 18:1312-1321.

Mori, M., Mise, K., Okuno, T., and Furusawa, I. 1992. Expression of Brome mosaic virus-encoded replicase genes in transgenic tobacco plants. J. Gen. Virol. 73:169-172.

Morishima, N., Ido, T., Hamada, H., Yoshimoto, E., Mizumoto, H., Takeuchi, S., Kiba, A., Hikichi, Y., and Okuno, T. 2003. Infectious in vitro transcripts from a cDNA clone of Tobacco mild green mosaic virus and its biological activity in host and nonhost plants and in their protoplasts. J. Gen. Plant Pathol. 69:335-338.

Nakajima, K., Sena, G., Nawy, T., and Benfey, P. N. 2001. Intercellular movement of the putative transcription factor SHR in root patterning. Nature 413:307-311.

Okinaka, Y., Mise, K., Suzuki, E., Okuno, T., and Furusawa, I. 2001. The $\mathrm{C}$ terminus of Brome mosaic virus coat protein controls viral cell-to-cell and long-distance movement. J. Virol. 75:5385-5390.

Okinaka, Y., Mise, K., Okuno, T., and Furusawa, I. 2003. Characterization of a novel barley protein, HCP1, that interacts with Brome mosaic virus coat protein. Mol. Plant-Microbe Interact. 16:352-359.

Pacha, R., and Ahlquist, P. 1991. Use of bromovirus RNA3 hybrids to study template specificity in viral RNA amplification. J. Virol. 65:3693-3703.

Quélo, I., Akhouayri, O., Prud'homme, J., and St-Arnaud, R. 2004a. GSK3 $\beta$-dependent phosphorylation of the $\alpha$ NAC coactivator regulates its nuclear translocation and proteasome-mediated degradation. Biochemistry 43:2906-2914.

Quélo, I., Gauthier, C., Hannigan, G., Dedhar, S., and St-Arnaud, R. 2004b. Integrin-linked kinase regulates the nuclear entry of the c-Jun coactivator $\alpha$-NAC and its coactivation potency. J. Biol. Chem. 279:43893-43899.

Rospert, S., Dubaquié, Y., and Gautschi, M. 2002. Nascent-polypeptideassociated complex. Cell. Mol. Life Sci. 59:1632-1639.

Schmitz, I., and Rao, A. L. N. 1996. Molecular studies on bromovirus cap- sid protein. I. Characterization of cell-to-cell movement-defective RNA3 variants of Brome mosaic virus. Virology 226:281-293.

Scholthof, H. B. 2005. Plant virus transport: motions of functional equivalence. Trends Plant Sci. 10:376-382.

Sessions, A., Yanofski, M. F., and Weigel, D. 2000. Cell-cell signaling and movement by the floral transcription factors LEAFY and APETALA1. Science 289:779-782.

Stilo, R., Liguoro, D., di Jeso, B., Leonardi, A., and Vito, P. 2003. The $\alpha-$ chain of the nascent polypeptide-associated complex binds to and regulates FADD function. Biochem. Biophys. Res. Commun. 303:1034-1041.

Takeda, A., Kaido, M., Okuno, T., and Mise, K. 2004. The C terminus of the movement protein of Brome mosaic virus controls the requirement for coat protein in cell-to-cell movement and plays a role in long-distance movement. J. Gen. Virol. 85:1751-1761.

Tamai, A., and Meshi, T. 2001. Tobamoviral movement protein transiently expressed in a single epidermal cell functions beyond multiple plasmodesmata and spreads multicellularly in an infection-coupled manner. Mol. Plant-Microbe Interact. 14:126-134.

Tamai, A., Kubota, K., Nagano, H., Yoshii, M., Ishikawa, M., Mise, K., and Meshi, T. 2003. Cucumovirus- and bromovirus-encoded movement functions potentiate cell-to-cell movement of tobamo- and potexviruses. Virology 315:56-67.

Waigmann, E., Ueki, S., Trutnyeva, K., and Citovsky, V. 2004. The ins and outs of nondestructive cell-to-cell and systemic movement of plant viruses. Crit. Rev. Plant Sci. 23:195-250.

Wiedmann, B., Sakai, H., Davis, T., and Wiedmann, M. 1994. A protein complex required for signal-sequence-specific sorting and translocation. Nature 370:434-440.

Xoconostle-Cázares, B., Xiang, Y., Ruiz-Medrano, R., Wang, H., Monzer, J., Yoo, B., McFarland, K., Franceschi, V., and Lucas, W. 1999. Plant paralog to viral movement protein that potentiates transport of mRNA into the phloem. Science 283:94-98.

Zambryski, P. 2004. Cell-to-cell transport of proteins and fluorescent tracers via plasmodesmata during plant development. J. Cell Biol. 162:165-168.

The online file was updated on November 17, 2015. The gel blot images originally published in Figure 2 had been sliced and incorrectly combined and have been replaced with the original unprocessed images, with corresponding changes to the caption and a callout on page 675 . 